\title{
The Role of the Innate Immune System in Alzheimer's Disease and Frontotemporal Lobar Degeneration: An Eye on Microglia
}

\author{
Elisa Ridolfi, Cinzia Barone, Elio Scarpini, and Daniela Galimberti \\ Neurology Unit, Department of Pathophysiology and Transplantation, University of Milan, Fondazione Cà Granda, \\ IRCCS Ospedale Maggiore Policlinico, Via F. Sforza 35, 20122 Milan, Italy
}

Correspondence should be addressed to Elisa Ridolfi; elisa.ridolfi@unimi.it

Received 4 April 2013; Accepted 4 July 2013

Academic Editor: Dan Frenkel

Copyright (C) 2013 Elisa Ridolfi et al. This is an open access article distributed under the Creative Commons Attribution License, which permits unrestricted use, distribution, and reproduction in any medium, provided the original work is properly cited.

In the last few years, genetic and biomolecular mechanisms at the basis of Alzheimer's disease (AD) and frontotemporal lobar degeneration (FTLD) have been unraveled. A key role is played by microglia, which represent the immune effector cells in the central nervous system (CNS). They are extremely sensitive to the environmental changes in the brain and are activated in response to several pathologic events within the CNS, including altered neuronal function, infection, injury, and inflammation. While short-term microglial activity has generally a neuroprotective role, chronic activation has been implicated in the pathogenesis of neurodegenerative disorders, including AD and FTLD. In this framework, the purpose of this review is to give an overview of clinical features, genetics, and novel discoveries on biomolecular pathogenic mechanisms at the basis of these two neurodegenerative diseases and to outline current evidence regarding the role played by activated microglia in their pathogenesis.

\section{Introduction}

Dementia is a chronic or progressive loss of cortical and subcortical functions resulting in cognitive decline, accompanied by disturbances of mood, behavior and personality, and synaptic loss [1]. Alzheimer's disease (AD) is the most prevalent dementia in the elderly, whereas the most common type of dementia in the presenile population $(<65$ years) is frontotemporal lobar degeneration (FTLD).

Alzheimer's disease affects up to $75 \%$ of the more than 35 million people suffering from dementia worldwide, and the prevalence is believed to double every 20 years [2]. FTLD instead represents nearly $20 \%$ of cases of early-onset dementia [3].

Both AD and FTLD are characterized by insoluble filamentous aggregates in the brain. They share this feature with Parkinson's disease, Lewy body dementia, and CreutzfeldtJakob disease. In particular, $\mathrm{AD}$ pathology is characterized by amyloid beta $(\mathrm{A} \beta)$ plaques and tau-containing neurofibrillary tangles (NFTs). The abnormal protein accumulation triggers a brain inflammatory reaction, inducing the production of a series of proinflammatory mediators and microglial activation [4]. Chronic microglial activation may contribute to the development and progression of neurodegenerative disorders, such as AD and FTLD.

The purpose of this review is to describe the main clinical and biomolecular features of AD and FTLD and to characterize the role of neuroinflammation in the pathogenesis of these diseases, with particular interest on the role played by microglia, which represents the immune system of the brain.

\section{Clinical Features of Alzheimer's Disease and Frontotemporal Lobar Degeneration}

2.1. Alzheimer's Disease. Alzheimer's disease is a progressive neurodegenerative disease, which is characterized by cognitive decline due to neuronal loss [5-7]. The hallmarks of $\mathrm{AD}$ are the extracellular $\mathrm{A} \beta$ plaque deposition (named senile plaques) and the intraneuronal NFTs of hyperphosphorylated tau protein [8]. Deposition of $\mathrm{A} \beta$ seems to be the first biological process during the pathogenesis of $\mathrm{AD}$, beginning many years before the appearance of symptoms. Also tau deposition in the brain, despite occurring later than $\mathrm{A} \beta$, starts before clinical onset of the disease. These changes are well reflected in the cerebrospinal fluid (CSF), in which increased 
levels of total tau and phosphorylated tau as well as decreased $\mathrm{A} \beta$ levels are altered early during the pathogenesis [9]. Several studies showed in fact that changes in these biomarkers can be seen in the preclinical stage of the disease (mild cognitive impairment, (MCI)), and this can be useful to establish MCI subjects that likely will turn into AD [10]. In a minority of cases, very often with an early onset (from the forth decade), $\mathrm{AD}$ is transmitted with an autosomal dominant pattern of inheritance. These cases are caused by autosomal dominant mutations in specific genes, including amyloid precursor protein $(A P P)$ and presenilin $(P S E N) 1$ and 2 [11]. However, except for PSEN2, all the mutations are fully penetrant. The majority of cases have a multifactorial pathogenesis, resulting from the combination of several genetic and environmental factors. The main gene associated with sporadic $\mathrm{AD}$ is the apolipoprotein E gene (APOE) [12].

\subsection{Frontotemporal Lobar Degeneration. Frontotemporal} lobar degeneration comprises a spectrum of clinical syndromes and is pathologically and genetically heterogeneous. The disease onset occurs between 45 and 65 years, and the prevalence is equal between men and women (see [17] for review). The most frequent clinical features are progressive changes in behavior, executive dysfunction, and language impairment.

Frontotemporal lobar degeneration can manifest with two major syndromes: behavioral variant frontotemporal dementia (bvFTD) and primary progressive aphasia (PPA). bvFTD is characterized by changes in behavior and personality, such as disinhibition, apathy, and loss of empathy, leading to a loss of social competence. bvFTD has been associated with symmetrical ventromedial frontal, orbital frontal, and insular atrophy and left anterior cingulate atrophy [13]. "The International Behavioral Variant FTD Criteria Consortium" established international consensus criteria for bvFTD: a diagnosis of bvFTD is based upon a three-tier, hierarchical classification system into "possible," defined by clinical criteria, "probable," supported by neuroimaging data, and "definite" bvFTD, confirmed by neuropathological evidence or the identification of a pathogenic mutation [14]. The clinical feature of PPA [15] is pronounced impairment in language, which may consist in deficits in language articulation, object-naming, syntax, and word comprehension. Primary progressive aphasia is further categorized into progressive nonfluent aphasia (PNFA), characterized by expressive or motor speech deficits with predominantly left perisylvian atrophy and semantic dementia (SD), described by a loss of semantic knowledge with associated atrophy of the left greater than the right anterior temporal lobes [16]. A third newly described subtype is named logopenic aphasia [15].

Furthermore, there is a significant clinical, pathological and genetic overlap between FTLD and amyotrophic lateral sclerosis (ALS). FTLD-ALS patients have a poor diagnosis with a mean survival of 2-3 years from the onset of first symptoms [16, 17]. Other diseases are closely related to FTLD, such as progressive supranuclear palsy, corticobasal syndrome, and FTD with parkinsonism [13].
The neuropathology of FTLD can be divided into four subtypes, according to its histology: with tau deposits (FTLDtau); with tau-negative, but with ubiquitin (FTLD-ubiquitin or FTLD-U) and TAR DNA binding protein (TDP)-43 positive inclusions (FTLD-TDP); with neuronal intermediate filament inclusions and cases with no detectable inclusions [18]. There are also a considerable number of TDP-43 negative FTLD-U cases with inclusions of fused-in-sarcoma protein (FUS), referred to as FTLD-FUS [13].

\section{Genetics}

3.1. Autosomal Dominantly Inherited Alzheimer's Disease. The APP gene is localized in the chromosome 21 and encodes for $\mathrm{A} \beta$ precursor, a transmembrane polypeptide of 770 amino acids. The release of $\mathrm{A} \beta$ follows at least two APP cleavages, processed by different classes of secretases. The first cleavage occurs within the extracellular domain by $\alpha$ or $\beta$-secretase, and the second proteolytic cut takes place in the transmembrane region by a third secretase, known as $\gamma$ secretase. In the amyloidogenic pathway, $A P P$ is processed sequentially by $\beta$ - and $\gamma$-secretase, with the generation of A $\beta 40$ - 42 fragments, which aggregate and form senile plaques [19-21]. The most common APP mutations occur in the transmembrane domain or in the $\gamma$-secretase cleavage site, leading to an increased $A \beta$ production $[20,21]$. Similarly, in the Down syndrome, the presence of a third APP copy gene causes an $\mathrm{A} \beta$ overproduction, which explains why the patient with Downs syndrome develops AD pathology in their brains [22]. Finally, substitutions that take place within the $\mathrm{A} \beta$ peptide result in a peptide that is more prone to cluster together and to form aggregates [20,21]. The other two genes involved in familial AD are components of $\gamma$-secretase complex, known as PSEN1, and its homologous PSEN2. PSEN1, which is in the chromosome 14, consists of 12 exons encoding for a transmembrane protein [23]. Its homologous PSEN2 is located in the chromosome 1, and encodes also for a transmembrane protein consisting of 12 exons [24]. PSEN1, or its isoform PSEN2, forms the catalytic core of $\gamma$-secretase complex together with nicastrin, anterior pharynx-defective 1, and presenilin enhancer 2. Most of PSEN1 mutations are missense mutations, which lead to an altered cleavage site in the $A P P$ sequence. The patients carrying these mutations have an autosomal dominant inheritance form of $\mathrm{AD}$ with a full penetrance and an age of onset of about 30 years old $[11,25]$. Conversely, PSEN2 mutation is an uncommon cause of AD with an incomplete penetrance and later onset [11]. Mutations in $P S E N 1 / 2$ genes cause an increased $\mathrm{A} \beta 40 / \mathrm{A} \beta 42$ ratio with increased $\mathrm{A} \beta 42$, that is, more incline to aggregate than $\mathrm{A} \beta 40$ $[20,21]$. Patients with different mutations in the same gene show heterogeneous clinical features [26].

\subsection{Autosomal Dominantly Inherited Frontotemporal Lobar} Degeneration. Frontotemporal lobar degeneration has a strong genetic component, demonstrated by the fact that about $40 \%$ of FTLD patients have a positive family history of dementia [27]. Several genes have been recognized to play a role in autosomal dominant FTLD: microtubule-associated 
protein tau (MAPT), progranulin $(G R N)$, and C9ORF72. In a minority of FTLD cases, valosin-containing-protein-(VCP) 1, transactive DNA-binding protein (TDP-43), FUS, and chromatin-modifying protein $2 \mathrm{~B}(C H M P 2 B)$ genes have been found to be responsible for the disease [3].

The first mutations causing FTD with parkinsonism (FTDP-17) were first found in chromosome 17 MAPT [28], which encodes for the tau protein, critical for microtubule assembly and stabilization in neurons. At present, more than 40 mutations have been identified in 134 pedigrees (http://www.molgen.vib-ua.be/ADMutations/default.cfm? $\mathrm{MT}=1 \& \mathrm{ML}=0 \&$ Page $=\mathrm{ADMDB})$. Mutations are predominantly clustered in exons $9-13$ of the microtubule-binding region near the alternatively spliced exon 10 [29] and mostly modify the normal function of tau $[30,31]$.

Mutations in a second gene in chromosome 17, named progranulin $(G R N)$, were discovered in 2006 [32, 33]. GRN mutations cause about $5-10 \%$ of all FTLD cases, varying depending on the population considered (see [17] for review). To date, 69 different $G R N$ mutations have been described in 231 families (http://www.molgen.vib-ua.be/ ADMutations/default.cfm?MT $=1 \& \mathrm{ML}=0 \&$ Page $=\mathrm{ADMDB})$. GRN mutations, which include frameshift, splice-site, and nonsense mutations, are distributed across the complete coding region and splice sites of the gene. These are lossof-function mutations, which lead to reduced functional protein, resulting in haploinsufficiency [13].

Recently, a hexanucleotide repeat expansion in the noncoding region of C9ORF72 has been recognized as the genetic abnormality on chromosome 9p21 underlying the majority cases of familial FTLD [3]. Majounie and colleagues observed pathological C9ORF72 repeat expansions in $11.4 \%$ of 1,381 FTLD patients of European origin, rising to $24.8 \%$ in familial patients, whereas a C9ORF72 repeats expansion frequency of $6.0 \%$ in sporadic FTLD [13]. The chromosome 9 expansion seems to mediate neurodegeneration through an RNA-mediated mechanism. Wild-type alleles contain less than 30 repeats, while mutated alleles have hundreds to thousands repeats [34].

The frequency of the hexanucleotide repeat expansions has been recently determined in a large population of 651 FTLD patients and the clinical characteristics of carriers and noncarriers compared. 39 FTLD patients $(6 \%)$ presented the pathogenic repeat expansion: 24 of these patients had a positive family history for dementia and/or ALS (61.5\%). The presentation with late-onset psychosis was more frequent in carriers than noncarriers, as well as the presence of cognitive impairment at onset. These data confirmed that the repeat expansion in C9ORF72 is a common cause of FTLD and, importantly, it is often associated with late-onset psychosis and memory impairment [35].

3.3. Sporadic Alzheimer's Disease: Genetic Risk Factors. A number of genetic variants contribute to the risk of developing sporadic AD. The gene that is strongly associated with $\mathrm{AD}$ is $A P O E$. This gene is located in chromosome 19 and consists of 4 exons, which encodes for a protein of 229 amino acids. There are three APOE isoforms: $\varepsilon 2, \varepsilon 3$, and $\varepsilon 4$. The $\varepsilon 3$ isoform is the most common allele among populations, while the $\varepsilon 2$ allele is found in only $1-5 \%$ of people and likely plays a protective role, by decreasing AD risk [36]. The $\varepsilon 4$ allele is found in the $50 \%$ patients affected by $\mathrm{AD}$ and confers a threefold increased risk for AD development [37]. $\mathrm{A} \beta$ trafficking, metabolism, and accumulation are regulated by APOE in a different manner by the three APOE isoforms. Perhaps this is the reason why the $\varepsilon 4$ allele confers a high AD risk, while the $\varepsilon 2$ allele is a protective factor [38-40]. Even though APOE $\varepsilon 4$ itself cannot be the cause of AD [41], the $\varepsilon 4$ isoform leads to an earlier onset of symptoms in APP or PSEN1 mutation carriers [42]. Many additional risk variants have been described on a candidate-based hypothesis. In the last few years, Genome Wide Association Studies (GWAS), carried out in large populations, identified novel risk genes, including complement receptor type I (CRI), phosphatidyl inositol binding clathrin assembly protein (PICALM), clusterin $(C L U)$, and bridging integrator 1 (BIN1).

\subsection{Susceptibility Genes and Risk Loci in Frontotemporal} Lobar Degeneration. Little is known about susceptibility genes contributing to the risk of developing FTLD.

There has been so far only one GWAS in FTLDTDP, which identified a possible susceptibility locus, which encompasses the gene TMEM106B on chromosome $7 \mathrm{p} 21$ [43]. The study identified three significantly associated single nucleotide polymorphisms (SNPs), which seemed to be related to an increased expression of TMEM106B, a condition that could be possibly involved in the pathogenesis of FTLDTDP [43].

Finch et al. tried to replicate the association of TMEM106B SNPs, using a large series of patients with FTLD with and without GRN mutations. They also performed in vivo studies in plasma and peripheral blood to test the hypothesis that TMEM106B SNPs regulate GRN expression levels and influence FTLD risk by modulating GRN expression. The authors found that TMEM106B SNPs significantly reduced the disease penetrance in patients with GRN mutations, potentially by modulating GRN levels [44].

Apart from this GWAS study, Rademakers and colleagues demonstrated that a common genetic variant (rs5848), located in the $3^{\prime}$-untranslated region of $G R N$ in a bindingsite for microRNA-659, was a major susceptibility factor for FTLD-U [34]. Another variant, in the first intron of GRN, was also reported to be associated with FTLD in another cohort of patients [45]. Details on additional candidate-based genes associated are reviewed in [46].

\section{Microglia and Neuroinflammation}

Microglia are the unique resident macrophages of the CNS, representing about $5-10 \%$ of the adult brain cell population [47]. In healthy conditions, microglia have a ramified morphology with a small, round soma and numerous branching processes [48]. During development, microglial cells are involved in different processes, such as clearance of dying or dead cells, elimination of excess axons, promotion of neuroaxonal growth, axonal guidance, neuronal differentiation, 
regulation of embryonic cortical precursor cell development, astrocyte proliferation, and angiogenesis. They are also able to release a variety of cell signaling factors like neurotrophins and extracellular matrix components [47].

A number of pathologic events, including altered neuronal function, infection, injury, and inflammation, rapidly activate microglia. Activated microglia change from a ramified to a hyperramified phenotype, proliferate, migrate to the site of damage, and secrete both cytotoxic and neurotrophic factors [49]. As the main cells of innate immunity of the CNS, microglia constitutively express the most important receptors (MHC I and II, chemokine receptors) at low levels [50]. During activation, the immunologically relevant molecules are upregulated and the appropriate antigen presented via MHC II [51]. Moreover, microglial cells can cross present exogenous antigens on MHC I to $\mathrm{CD}^{+}{ }^{+} \mathrm{T}$ cells [52].

Microglia can present two distinct molecular phenotypes and effector functions depending on the activation pathway. The M1 phenotype is induced by classic activation of microglia and is characterized by production of proinflammatory cytokines, such as IL- $1 \beta$ and TNF- $\alpha$, and free radicals such as reactive oxygen species (ROS). It plays a central role in the defense against pathogens and tumor cells but can also damage healthy cells, like neurons and glial cells. The alternative M2 anti-inflammatory phenotype is induced by IL- 4 and IL-13 and expresses CD206 and arginase 1 , which downregulate inflammation and promote tissue remodeling/repair and angiogenesis [47].

While short-term microglial activity has generally a neuroprotective role, chronic activation has been implicated in the pathogenesis of neurodegenerative disorders. The exact mechanism leading to microglial overactivation is still not fully understood, but glial-neuronal crosstalk seems to be central, as well as microglia and astrocyte interaction. Proinflammatory cytokines secreted by activated microglia inhibit astrocyte gap junction communication, which influences the role of astrocytes in providing neuronal support [50]. Moreover, activated microglia can release the neurotransmitter glutamate, which trigger excitotoxic neurodegeneration and cell death of astrocytes and oligodendrocytes [47].

4.1. Microglia Activation and the Role of Inflammation in $A D$. Lines of evidence of inflammatory involvement in $\mathrm{AD}$ were first observed by Alois Alzheimer in autopsied brains from patients with $\mathrm{AD}[53,54]$. This hypothesis is supported by the epidemiologic studies which show that patients treated with nonsteroidal anti-inflammatory drugs (NSAIDs) had a reduced incidence of $\mathrm{AD}$ [55-57]. Later, neuron models demonstrated that the metabolites and products of inflammatory reaction, were neurotoxic $[58,59]$. These products of inflammatory reactions may initiate and promote neuronal degeneration in $\mathrm{AD}[60]$.

Neuroinflammation depends essentially on microglia and astrocytes activation that respond to various injuries and stimulations, through the expression of inflammatory factors such as cytokines and chemokines, and the release of reactive oxygen species (ROS) and nitric oxide (NO) that finally cause oxidative stress [61-64]. Many studies, in fact, show that oxidative stress responsive transcription factors, such as NF$\kappa \mathrm{B}$ and $\mathrm{CHOP}$, are directly linked with the inflammatory pathway by regulating proinflammatory genes [65-67].

Cytotoxic activation and inflammatory factors stimulate glial cells to the release of several proinflammatory signals generating a vicious circle between neuroinflammation and oxidative stress that results in a self-sustaining inflammatory condition [68].

This inflammatory state could, moreover, modify intercellular communication through the deregulation of gap junction channel and hemichannel [69]. In AD, astrocytes show a decreased gap junctional intercellular communication (GJIC) and an increased hemichannel functionality [7074]. During $A D$ progression, $A \beta$ accumulation increases hemichannel activity, which generates $\mathrm{Ca}^{2+}$ diffusion also through GJIC. This influx raises the intracellular $\mathrm{Ca}^{2+}$ concentration in the neighbors astrocytes cells allowing the release of glutamate and activation of neuronal NMDA receptors [75]. The hemichannel activation, instead, drives the release of ATP that finally activates the purinergic receptor (P2). P2 and NMDA affect electrochemical and $\mathrm{Ca}^{2+}$ imbalance in neurons, which leads finally to cell death [76]. Similarly, decreased GJIC may defend the physiological intercellular diffusion of nutrient and metabolites, essential for growth and survival of neurons, generating cell death. On the other hand, the decreased GJIC may be a defensive mechanism to avoid the diffusion of death signal and toxic molecules through cells [77]. In this contest, even though the main $\mathrm{AD}$ hallmarks are senile plaques and neurofibrillary tangles, several recent studies have showed that activated microglia are one of the principal players of neuroinflammation, together with $A \beta$ plaques deposition or astrocytes stimulation [78].

Wisniewski et al. [79], by electron microscopic analysis, observed that at least $80 \%$ of $\mathrm{A} \beta$ plaques colocalize with activated microglia in the brain of $\mathrm{AD}$ patients $[79,80]$. In vivo and in vitro experiments suggest that microglia, recruited in $A \beta$ plaques site, are able to surround and phagocytize $\mathrm{A} \beta$ peptides. This mechanism is regulated by Toll-like receptor, suggesting an impairment of the immune system in AD pathogenesis. In the same way, astrocytes cells, which provide trophic and metabolic support to neurons, also regulate phagocytic activity of microglia cells [81-83]. The lines of evidences show that under chronic inflammatory condition, astrocytes are unable to preserve the scavenger role of microglia suggesting an impairment of this physiological mechanism in AD patients [84].

$\mathrm{A} \beta$ plays also an important role in the regulation of proteasome activity witch is essential for the degradation of ubiquitin-conjugated proteins [85]. The deregulation of this mechanism seems to be involved in the neuroinflammation neurodegeneration process, and $\mathrm{A} \beta$ is one of the factors that could inhibit proteasome functions [86-90]. Moreover, $A \beta$ deposition is responsible for microglia activation in a way strictly dependent on amyloid load; evidence of this comes from many experiments, where APP gene disruption reduces microglia activation and decreases neuroinflammation [91]. 
$\mathrm{A} \beta$ contributes to enhance inflammatory response by NF- $\kappa \mathrm{B}$ stimulation, a nuclear factor implicated in cytokine production and also regulates the extracellular signalregulated kinase (ERK) and mitogen-activated protein kinase (MAPK) pathway that leads to cytokines and chemokine production [92, 93]. Several proinflammatory cytokines and chemokines have been found dysregulated in $\mathrm{AD}$ patients [94]. IL-1, IL-6, and TNF- $\alpha$, which are proinflammatory cytokines, were found upregulated in $\mathrm{AD}$ patients [95]. In particular, IL-1 induces microglia and astrocytes activation, enhancing inflammation; moreover, it stimulates acetylcholinesterase and iNOS enzymatic activity [96-98]. IL-6 supports astrogliosis and stimulates the release of acute phase protein [99-101]. In addition, TNF- $\alpha$ expression is regulated by CD40L. Activated microglia, treated with CD40L, lead to an increased TNF- $\alpha$ level that results in neuron injury. The evidence comes from the APP mice deficient for CD40 that shows decreased microglia activation and reduction of inflammatory response [102]. In vitro analysis showed that $\mathrm{A} \beta$ stimulates the secretion of specific chemokines, such as CCL2 and CCL3. In AD patients, where their levels are elevated, CCL2 and CCL3 recruit astrocytes and microglia cells to $\mathrm{A} \beta$ plaques site increasing neuroinflammation [103, 104]. Cytokines and chemokines are altered in CSF from patients compared with controls. Galimberti et al. showed that IL-11 levels are increased in CSF of mild AD and FTLD patients and positively correlated with the Mini Mental State Examination (MMSE) score. On the contrary, MCP1 and IL-8 levels were increased in all $\mathrm{AD}$ and in almost FTLD patients. Moreover, IP10 concentration was elevated in CSF from AD patients as well as subjects with MCI but was unchanged in FTLD patients $[105,106]$. By putting these data together, these studies suggest that IP-10 probably is involved only in $\mathrm{AD}$ pathology. On the contrary, MCP1 and IL-11, which were found upregulated in FTLD and others neurodegenerative disease, may be implicated in a common step shared by these pathologies. The positive correlation between high MMSE score and the IL-11/IP-10 peaks detected in CFS suggests that up-regulation of these cytokines is an early event in the pathogenesis of AD/FTLD, that is, not observed in the late stages of the disease, implying that the high level of proinflammatory cytokine represents an early and transitory effort of immune cells to restore brain health $[105,107]$. Additionally, the complement system is active in the early stage of the disease. In fact, $A \beta$ is able to activate the complement system by alternative pathway [108]. Nonetheless, the complement activation produces inflammation and cell damage; studies in mice models showed that the complement system had also neuroprotective roles. These studies demonstrated that the complement complex inhibition increased $\mathrm{A} \beta$ deposition, suggesting that the complement complex is essential for clearance of apoptotic cells, debris cells, and toxic protein aggregates [109-111].

Recent investigations showed that activated microglia and inflammation are not always detrimental but can have a reparative role in neuronal damage. For example, CD45, a bound protein-tyrosine phosphatase, is highly expressed in activated microglia of $\mathrm{AD}$ patients rather than controls [112]. Tan et al. inhibited CD45 activity to investigate its role in reactivity of microglia to the $\mathrm{A} \beta$ protein [113]. The results showed an increased level of TNF- $\alpha$ and other toxic molecules, which generated neuron damage. The use of CD45 agonist decreased TNF- $\alpha$ expression and oxide nitric production, downregulating microglial activation. The conclusion is that $\mathrm{CD} 45$ could play beneficial and protective effects in $\mathrm{AD}$ [114].

Other studies show that sometimes proinflammatory cytokines promote beneficial neuroinflammation, decreasing AD mice amyloidosis. Shaftel et al. [115] created a transgenic mouse IL- $\beta^{\mathrm{XAT}}$ to study the role of IL-1 $\beta$ in neuroinflammation. This transgenic mouse overexpressed IL- $\beta$ in a specific temporal and spatial manner following FIV-Cre injection. IL$\beta^{\mathrm{XAT}}$ mouse showed a high neuroinflammation caused by astrocytes and microglia activation. APP mice were crossed with IL- $\beta^{\mathrm{XAT}}$ mice, showing a drastic reduction of $\mathrm{A} \beta$ plaques and an increased phagocytosis activity [115]. These data suggest that IL- $\beta$ expression leads to a beneficial neuroinflammation that enhances $\mathrm{A} \beta$ removal. Other investigators obtained the same results by expressing IFN- $\gamma$, in TgCRND8 mice, a mouse model of cerebral amyloidosis. The analysis, after IFN- $\gamma$ injection, showed a remarkable decrease of $\mathrm{A} \beta$ plaques [116]. Taken together, these data suggest that certain forms of inflammation and microglia activation are quite helpful in neurodegenerative pathology, such as $\mathrm{AD}$ [117].

4.2. Microglia, Tau, and Progranulin: Role in FTLD. Cagnin et al. [118] first observed microglial activation in FTLD. They used positron emission tomography and a marker of "peripheral benzodiazepine sites," $\left[{ }^{11} \mathrm{C}\right](\mathrm{R})-\mathrm{PK} 11195$, which is upregulated on activated microglia during progressive tissue pathology [119]. They demonstrated an increased binding of $\left[{ }^{11} \mathrm{C}\right](\mathrm{R})$-PK11195 in the typically affected frontotemporal brain regions, which implied the presence of activated microglia response reflecting progressive neuronal degeneration [118].

Interestingly, activated microglia express progranulin [120-122]. Progranulin expression greatly increased in response to experimental traumatic spinal cord injury in a mouse model, and microglia were the primary sources of progranulin after injury [120]. Tanaka et al. [121] demonstrated that progranulin deficiency induced exacerbated inflammatory responses associated with activated microglia, such as excessive increase of CD68-positive cells, which is a marker for activated microglia, and TGF $\beta$-Smad3 signaling, a central mediator initiating formation of the glial scar [123], excessive protein oxidation and laminin immunoreactivity after traumatic brain injury [121].

Yin et al. [124] tried to understand the mechanism by which loss of function mutations in GRN cause FTLD. They generated conditional GRN knock-out mice, with the expectation that GRN gene deletion might be embryonic lethal. Instead, it was not the case. Initially, they observed that $G R N$-deficient macrophages produced more proinflammatory cytokines and chemokines, such as CCL2, CXCL1, IL-6, IL-12p 40, and TNF, but less anti-inflammatory cytokine IL-10 compared to wild-type (wt) macrophages, when exposed to 
bacterial lipopolysaccharide. However, GRN-deficient mice failed to clear bacterial infection as fast as wt mice and were characterized by an exaggerated inflammatory tissue damage. Immunostaining of brain sections for CD68 revealed greater activation of microglia with age in GRN-deficient mice than wt mice. Moreover, GRN-deficient microglia responded to inflammatory stimuli by becoming more cytotoxic than wt microglia, and GRN-deficient neurons were more susceptible than wt to damage by activated microglia and by certain cytotoxic stresses, such as depletion of glucose and oxygen. They also showed enhanced hippocampal ubiquitin immunostaining and increased phosphorylation of TDP43 in the hippocampus and thalamus of old GRN-deficient mice. The authors thus hypothesized that FTLD may arise from the congruence of two independent phenotypes of GRN insufficiency: deregulated inflammation and increased neuronal vulnerability to damage [124]. In another study, the same authors assessed the behavioral profile of GRN-deficient mice from 1 to 18 months (mo) of age, finding impairment in social recognition tasks. Behavioral deficits appeared early in the disease (at 1 mo of age), and they were still present at 18 mo of age. These findings were consistent with the behavioral and personality changes observed in FTLD patients. A possible mechanism underlying GRN-deficiency-linked behavioral deficits is that the anti-inflammatory action of GRN may be indispensable for a balanced immune response in the brain [125].

Martens et al. [126] demonstrated that the loss of $G R N$ resulted in increased neuron loss in response to injury in the CNS. When exposed acutely to $1^{\prime}$-methil-4( $2^{\prime}$-methylphenyl)-1,2,3,6-tetrahydrophine (MPTP), a neurotoxin that targets the dopaminergic neurons of the substantia nigra pars compacta (SNpc), mice lacking GRN $\left(\mathrm{Grn}^{-/-}\right)$ showed an exaggerated, prolonged inflammatory response in activated microglia and that this mechanism likely contributed to enhanced neuron death following injury. Consistent with this, conditional mutants lacking GRN in microglia exhibited MPTP-induced phenotypes similar to $\mathrm{Grn}^{-/-}$mice. Selective depletion of GRN from microglia in mixed cortical cultures resulted in increased death of wild-type neurons in the absence of injury. Furthermore, $\mathrm{Grn}^{-1-}$ microglia treated with LPS/IFN- $\gamma$ exhibited an amplified inflammatory response and conditioned media from these microglia promoted death of cultured neurons. These results indicated that $G R N$ deficiency leads to dysregulated microglial activation and thereby contributed to increased neuron loss with injury, revealing a role for $G R N$ in the attenuation of neuroinflammation and suggesting that this mechanism contributed to neurodegeneration in GRN-deficient FTLD. Further, GRN may attenuate inflammation and neuron death in other forms of neurodegeneration or CNS injury [126].

Interestingly, progranulin also seems to play a role in the activation of microglia in AD. GRN polymorphisms have been associated with $\mathrm{AD}[127,128]$, and progranulin has been found to colocalize with $\mathrm{A} \beta$ plaques in brains of $\mathrm{AD}$ patients [129] and in some lines of transgenic mice models of AD [130]. Recently, Pickford et al. studied the effect of progranulin on neurons and microglia [131]. Using microarray and cytokine arrays, they found out that progranulin increased the secretion of leptin and Th2 cytokines, such as IL-4, IL-10, and IL-5, which have been associated with neuroprotection. Moreover, progranulin reduced the secretion of TRAIL, a member of the TNF superfamily, which is a regulator of apoptosis and is upregulated in the $\mathrm{AD}$ patients' brains [132]. Reduction of TRAIL secretion may be a neuroprotective mechanism of progranulin. They observed that progranulin promoted chemotaxis and endocytosis of extracellular peptides, including $\mathrm{A} \beta$, by microglia. In addition, progranulin induced differentiation of microglia into the M2 anti-inflammatory phenotype. So, the activation of progranulin pathway could be a new strategy to promote microglial clearance of $\mathrm{A} \beta$ without the activation of cytotoxic cytokines [131].

Bellucci et al. [4] focused instead their attention on a mutation of tau protein. In particular, they studied the effect of P301S mutated human tau protein in a patient with FTLDP-17T, a hereditary neurodegenerative disorder characterized by a spectrum of clinical phenotypes ranging from an FTLD-predominant to a parkinsonism-predominant type, linked to chromosome 17 with tau mutations [133]. In the cortex and hippocampus of the P301S patient, activated microglia, expressing CD68, and infiltrating macrophages were detected. These cells were particularly concentrated in the surroundings of phosphorylated (phospho)-taupositive neurons. Moreover, the presence of CD68 positive cells around blood vessels indicated that the reactive microgliosis was probably accompanied by a remarkable macrophage infiltration. Activated microglia evolved also in a macrophagic state, a condition that happens during chronic neuroinflammation, and phospho-tau-positive neurons released activating signals, such as IL-1 $\beta$ and COX 2 . IL- $1 \beta$ acts as a chemotactic factor, and COX2 induces the production of prostaglandins, which may activate several intracellular kinases able to phosphorylate tau on specific sites [134]. Based on these results, the authors concluded that microglial activation and the production of proinflammatory mediators by phospho-tau-positive neurons may differentially contribute to neuronal death and disease progression in neurodegenerative tauopathies [4].

\section{Conclusions}

In the last few years, genetic and molecular aspects at the basis of AD and FTLD have been better clarified, including the role of genes, inflammatory factors, and brain immune cells, microglia. Regarding autosomal dominant forms of AD and FTLD, many new genes have been identified, and new diagnostic criteria have been proposed. Concerning events at the basis of the diseases, it has become clearer and clearer that microglia play a crucial role, displaying both inflammatory and neuroprotective properties.

Activated microglia could help in the recovery process or potentially aggravate CNS damage. In addition, a link has found between products of mutated genes, microglia, and inflammatory factors. A better understanding of such 
mechanisms, responsible for the development and progression of neurodegenerative disorders, will be a challenge for the future, with the aim of identifying specific targets for a tailored therapy.

\section{Authors' Contribution}

Elisa Ridolfi and Cinzia Barone contributed equally to this work.

\section{References}

[1] J. Götz, L. M. Ittner, and N. Schonrock, "Alzheimer's disease and frontotemporal dementia: prospects of a tailored therapy?" Medical Journal of Australia, vol. 185, no. 7, pp. 381-384, 2006.

[2] Alzheimer's Association, "2012 Alzheimer's disease facts and figures," Alzheimer's and Dementia, vol. 8, no. 2, pp. 131-168, 2012.

[3] R. E. Seltman and B. R. Matthews, "Frontotemporal lobar degeneration: epidiemology, pathology, diagnosis and management," CNS Drugs, vol. 26, no. 10, pp. 841-870, 2012.

[4] A. Bellucci, O. Bugiani, B. Ghetti, and M. G. Spillantini, "Presence of reactive microglia and neuroinflammatory mediators in a case of frontotemporal dementia with P301S mutation," Neurodegenerative Diseases, vol. 8, no. 4, pp. 221-229, 2011.

[5] G. M. McKhann, D. S. Knopman, H. Chertkow et al., "The diagnosis of dementia due to Alzheimer's disease: recommendations from the National Institute on Aging-Alzheimer's Association workgroups on diagnostic guidelines for Alzheimer's disease," Alzheimer's and Dementia, vol. 7, no. 3, pp. 263-269, 2011.

[6] M. S. Albert, S. T. DeKosky, D. Dickson et al., "The diagnosis of mild cognitive impairment due to Alzheimer's disease: recommendations from the National Institute on AgingAlzheimer's Association workgroups on diagnostic guidelines for Alzheimer's disease," Alzheimer's and Dementia, vol. 7, no. 3, pp. 270-279, 2011.

[7] R. A. Sperling, P. S. Aisen, L. A. Beckett et al., “Toward defining the preclinical stages of Alzheimer's disease: recommendations from the National Institute on Aging-Alzheimer's Association workgroups on diagnostic guidelines for Alzheimer's disease," Alzheimer's and Dementia, vol. 7, no. 3, pp. 280-292, 2011.

[8] H. Braak and E. Braak, "Neuropathological stageing of Alzheimer-related changes," Acta Neuropathologica, vol. 82, no. 4, pp. 239-259, 1991.

[9] C. R. Jack Jr., D. S. Knopman, W. J. Jagust et al., "Hypothetical model of dynamic biomarkers of the Alzheimer's pathological cascade," The Lancet Neurology, vol. 9, no. 1, pp. 119-128, 2010.

[10] P. Buchhave, L. Minthon, H. Zetterberg, Å. K. Wallin, K. Blennow, and O. Hansson, "Cerebrospinal fluid levels of $\beta$ amyloid 1-42, but not of tau, are fully changed already 5 to 10 years before the onset of Alzheimer dementia," Archives of General Psychiatry, vol. 69, no. 1, pp. 98-106, 2012.

[11] L. M. Bekris, C.-E. Yu, T. D. Bird, and D. W. Tsuang, "Review article: genetics of Alzheimer disease," Journal of Geriatric Psychiatry and Neurology, vol. 23, no. 4, pp. 213-227, 2010.

[12] B. V. Hooli G Mohapatra, M. Mattheisen et al., "Role of common and rare APP DNA sequence variants in Alzheimer disease," Neurology, vol. 78, no. 16, pp. 1250-1257, 2012.

[13] A. Sieben, T. van Langenhove, S. Engelborghs et al., "The genetics and neuropathology of frontotemporal lobar degeneration," Acta Neuropathologica, vol. 124, no. 3, pp. 353-372, 2012.
[14] K. Rascovsky, J. R. Hodges, D. Knopman et al., "Sensitivity of revised diagnostic criteria for the behavioural variant of frontotemporal dementia," Brain, vol. 134, no. 9, pp. 2456-2477, 2011.

[15] M. L. Gorno-Tempini, A. E. Hillis, S. Weintraub et al., "Classification of primary progressive aphasia and its variants," Neurology, vol. 76, no. 11, pp. 1006-1014, 2011.

[16] K. A. Josephs, J. R. Hodges, J. S. Snowden et al., "Neuropathological background of phenotypical variability in frontotemporal dementia," Acta Neuropathologica, vol. 122, no. 2, pp. 137-153, 2011.

[17] R. Ferrari, A. Thumma, and P. Momeni, "Molecular genetics of frontotemporal dementia," Acta Neuropathologica, vol. 124, no. 3, pp. 373-382, 2012.

[18] L. Sun and J. L. Eriksen, "Recent insights into the involvement of progranulin in frontotemporal dementia," Current Neuropharmacology, vol. 9, no. 4, pp. 632-642, 2011.

[19] T. Tomiyama, T. Nagata, H. Shimada et al., "A new amyloid $\beta$ variant favoring oligomerization in Alzheimer's-type dementia," Annals of Neurology, vol. 63, no. 3, pp. 377-387, 2008.

[20] T. Iwatsubo, D. M. A. Mann, A. Odaka, N. Suzuki, and Y. Ihara, "Amyloid $\beta$ protein $(\mathrm{A} \beta)$ deposition: $\mathrm{A} \beta 42(43)$ precedes $\mathrm{A} \beta 40$ in Down syndrome," Annals of Neurology, vol. 37, no. 3, pp. 294299, 1995.

[21] A. Tandon, E. Rogaeva, M. Mullan, and P. H. St. GeorgeHyslop, "Molecular genetics of Alzheimer's disease: the role of $\beta$-amyloid and the presenilins," Current Opinion in Neurology, vol. 13, no. 4, pp. 377-384, 2000.

[22] K. E. Wisniewski, H. M. Wisniewski, and G. Y. Wen, "Occurrence of neuropathological changes and dementia of Alzheimer's disease in Down's syndrome," Annals of Neurology, vol. 17, no. 3, pp. 278-282, 1985.

[23] S. Baulac, M. J. LaVoie, W. T. Kimberly et al., "Functional $\gamma$-secretase complex assembly in Golgi/trans-Golgi network: interactions among presenilin, nicastrin, Aphl, Pen-2, and $\gamma$ secretase substrates," Neurobiology of Disease, vol. 14, no. 2, pp. 194-204, 2003.

[24] W. T. Kimberly, M. J. LaVoie, B. L. Ostaszewski, W. Ye, M. S. Wolfe, and D. J. Selkoe, " $\gamma$-Secretase is a membrane protein complex comprised of presenilin, nicastrin, aph-1, and pen-2," Proceedings of the National Academy of Sciences of the United States of America, vol. 100, no. 11, pp. 6382-6387, 2003.

[25] H. Karlstrom, W. S. Brooks, J. B. J. Kwok et al., "Variable phenotype of Alzheimer's disease with spastic paraparesis," Journal of Neurochemistry, vol. 104, no. 3, pp. 573-583, 2008.

[26] M. Cruts, C. M. van Duijn, H. Backhovens et al., "Estimation of the genetic contribution of presenilin-1 and -2 mutations in a population-based study of presenile Alzheimer disease," Human Molecular Genetics, vol. 7, no. 1, pp. 43-51, 1998.

[27] J. S. Goldman, J. M. Farmer, E. M. Wood et al., "Comparison of family histories in FTLD subtypes and related tauopathies," Neurology, vol. 65, no. 11, pp. 1817-1819, 2005.

[28] M. Baker, I. R. Mackenzie, S. M. Pickering-Brown et al., "Mutations in progranulin cause tau-negative frontotemporal dementia linked to chromosome 17," Nature, vol. 442, no. 7105, pp. 916-919, 2006.

[29] R. Rademakers, M. Cruts, and C. van Broeckhoven, "The role of tau (MAPT) in frontotemporal dementia and related tauopathies," Human Mutation, vol. 24, no. 4, pp. 277-295, 2004.

[30] L. Buée and A. Delacourte, "Comparative biochemistry of tau in progressive supranuclear palsy, corticobasal degeneration, 
FTDP-17 and Pick's disease," Brain Pathology, vol. 9, no. 4, pp. 681-693, 1999.

[31] M. Goedert and R. Jakes, "Mutations causing neurodegenerative tauopathies," Biochimica et Biophysica Acta, vol. 1739, no. 2, pp. 240-250, 2005.

[32] M. Cruts, I. Gijselinck, J. van der Zee et al., "Null mutations in progranulin cause ubiquitin-positive frontotemporal dementia linked to chromosome 17q21," Nature, vol. 442, no. 7105, pp. 920-924, 2006.

[33] B. F. Boeve, M. Baker, D. W. Dickson et al., "Frontotemporal dementia and parkinsonism associated with the IVS1+1G $\rightarrow$ A mutation in progranulin: a clinicopathologic study," Brain, vol. 129, no. 11, pp. 3103-3114, 2006.

[34] M. DeJesus-Hernandez, I. R. Mackenzie, B. F. Boeve et al., "Expanded GGGGCC hexanucleotide repeat in noncoding region of C9ORF72 causes chromosome 9p-linked FTD and ALS," Neuron, vol. 72, no. 2, pp. 245-256, 2011.

[35] D. Galimberti, C. Fenoglio, and M. Serpente, "Autosomal dominant frontotemporal lobar degeneration due to the C9ORF72 hexanucleotide repeat expansion: late-onset psychotic clinical presentation," Biological Psychiatry, 2013.

[36] R. W. Mahley, "Apolipoprotein E: cholesterol transport protein with expanding role in cell biology," Science, vol. 240, no. 4852, pp. 622-630, 1988.

[37] E. H. Corder, A. M. Saunders, W. J. Strittmatter et al., "Gene dose of apolipoprotein E type 4 allele and the risk of Alzheimer's disease in late onset families," Science, vol. 261, no. 5123, pp. 921923, 1993.

[38] E. M. Castano, F. Prelli, T. Wisniewski et al., "Fibrillogenesis in alzheimer's disease of amyloid $\beta$ peptides and apolipoprotein E," Biochemical Journal, vol. 306, no. 2, pp. 599-604, 1995.

[39] J. Ma, A. Yee, H. B. Brewer Jr., S. Das, and H. Potter, "Amyloidassociated proteins $\alpha 1$-antichymotrypsin and apolipoprotein E promote assembly of Alzheimer $\beta$-protein into filaments," Nature, vol. 372, no. 6501, pp. 92-94, 1994.

[40] T. Wisniewski, E. M. Castaño, A. Golabek, T. Vogel, and B. Frangione, "Acceleration of Alzheimer's fibril formation by apolipoprotein E in vitro," The American Journal of Pathology, vol. 145, no. 5, pp. 1030-1035, 1994.

[41] P. Pastor, C. M. Roe, A. Villegas et al., "Apolipoprotein E\&4 modifies Alzheimer's disease onset in an E280A PS1 kindred," Annals of Neurology, vol. 54, no. 2, pp. 163-169, 2003.

[42] A. D. Roses, "Apolipoprotein E and Alzheimer's disease: a rapidly expanding field with medical and epidemiological consequences," Annals of the New York Academy of Sciences, vol. 802, pp. 50-57, 1996.

[43] V. M. van Deerlin, P. M. A. Sleiman, M. Martinez-Lage et al., "Common variants at $7 \mathrm{p} 21$ are associated with frontotemporal lobar degeneration with TDP-43 inclusions," Nature Genetics, vol. 42, no. 3, pp. 234-239, 2010.

[44] N. Finch, M. M. Carrasquillo, M. Baker et al., "TMEM106B regulates progranulin levels and the penetrance of FTLD in GRN mutation carriers," Neurology, vol. 76, no. 5, pp. 467-474, 2011.

[45] D. Galimberti, C. Fenoglio, F. Cortini et al., "GRN variability contributes to sporadic frontotemporal lobar degeneration," Journal of Alzheimer's Disease, vol. 19, no. 1, pp. 171-177, 2010.

[46] C. Cerami, E. Scarpini, S. F. Cappa, and D. Galimberti, "Frontotemporal lobar degeneration: current knowledge and future challenges," Journal of Neurology, vol. 259, no. 3, pp. 2278-2286, 2012.
[47] M. Czeh, P. Gressens, and A. M. Kaindl, "The yin and yang of microglia," Developmental Neuroscience, vol. 33, no. 3-4, pp. 199-209, 2011.

[48] J. A. Smith, A. Das, S. K. Ray, and N. L. Banik, "Role of proinflammatory cytokines released from microglia in neurodegenerative diseases," Brain Research Bulletin, vol. 87, no. 1, pp. 10-20, 2012.

[49] G. A. Garden and T. Möller, "Microglia biology in health and disease," Journal of Neuroimmune Pharmacology, vol. 1, no. 2, pp. 127-137, 2006.

[50] L. Walter and H. Neumann, "Role of microglia in neuronal degeneration and regeneration," Seminars in Immunopathology, vol. 31, no. 4, pp. 513-525, 2009.

[51] M. B. Graeber and W. J. Streit, "Microglia: biology and pathology," Acta Neuropathologica, vol. 119, no. 1, pp. 89-105, 2010.

[52] C. Beauvillain, S. Donnou, U. Jarry et al., "Neonatal and adult microglia cross-present exogenous antigens," GLIA, vol. 56, no. 1, pp. 69-77, 2008.

[53] J. M. Rubio-Perez and J. M. Morillas-Ruiz, "A review: inflammatory process in Alzheimer's disease, role of cytokines," The Scientific World Journal, vol. 2012, no. 6, Article ID 756357, 2012.

[54] K. Takami, K. Terai, A. Matsuo, D. G. Walker, and P. L. McGeer, "Expression of presenilin-1 and -2 mRNAs in rat and Alzheimer's disease brains," Brain Research, vol. 748, no. 1-2, pp. 122-130, 1997.

[55] J. C. S. Breitner, K. A. Welsh, M. J. Helms et al., "Delayed onset of Alzheimer's disease with nonsteroidal anti-inflammatory and histamine H2 blocking drugs," Neurobiology of Aging, vol. 16, no. 4, pp. 523-530, 1995.

[56] J. C. S. Breitner, B. A. Gau, K. A. Welsh et al., "Inverse association of anti-inflammatory treatments and Alzheimer's disease: initial results of a co-twin control study," Neurology, vol. 44, no. 2, pp. 227-232, 1994.

[57] R. Myllykangas-Luosujarvi and H. Isomaki, "Alzheimer's disease and rheumatoid arthritis," British Journal of Rheumatology, vol. 33, no. 5, pp. 501-502, 1994.

[58] J. M. Rozemuller, P. Eikelenboom, S. T. Pals, and F. C. Stam, "Microglial cells around amyloid plaques in Alzheimer's disease express leucocyte adhesion molecules of the LFA-1 family," Neuroscience Letters, vol. 101, no. 3, pp. 288-292, 1989.

[59] K.N. Prasad, F.G. La Rosa, and J.E. Prasad, "Prostaglandins act as neurotoxin for differentiated neuroblastoma cells in culture and increase levels of ubiquitin and $\beta$-amyloid," In Vitro Cellular and Developmental Biology, vol. 34, no. 3, pp. 265-274, 1998.

[60] Y.-J. Lee, S. B. Han, S.-Y. Nam, K.-W. Oh, and J. T. Hong, "Inflammation and Alzheimer's disease," Archives of Pharmacal Research, vol. 33, no. 10, pp. 1539-1556, 2010.

[61] R. von Bernhardi, "Glial cell dysregulation: a new perspective on Alzheimer disease," Neurotoxicity Research, vol. 12, no. 4, pp. 215-232, 2007.

[62] G. J. Harry, C. Lefebvre d'Hellencourt, A. Bruccoleri, and D. Schmechel, "Age-dependent cytokine responses: trimethyltin hippocampal injury in wild-type, APOE knockout, and APOE4 mice," Brain, Behavior, and Immunity, vol. 14, no. 4, pp. 288-304, 2000.

[63] G. Ramírez, S. Rey, and R. Von Bernhardi, "Proinflammatory stimuli are needed for induction of microglial cell-mediated A $\beta$ PP244-C and A $\beta$-neurotoxicity in hippocampal cultures," Journal of Alzheimer's Disease, vol. 15, no. 1, pp. 45-59, 2008.

[64] R. Von Bernhardi, J. E. Tichauer, and J. Eugenín, "Agingdependent changes of microglial cells and their relevance for 
neurodegenerative disorders," Journal of Neurochemistry, vol. 112, no. 5, pp. 1099-1114, 2010.

[65] A. Salminen, J. Ojala, A. Kauppinen, K. Kaarniranta, and T. Suuronen, "Inflammation in Alzheimer's disease: amyloid- $\beta$ oligomers trigger innate immunity defence via pattern recognition receptors," Progress in Neurobiology, vol. 87, no. 3, pp. 181194, 2009.

[66] W. Zhang and D. Stanimirovic, "Current and future therapeutic strategies to target inflammation in stroke," Current Drug Targets, vol. 1, no. 2, pp. 151-166, 2002.

[67] L. Tan, P. Schedl, H.-J. Song, D. Garza, and M. Konsolaki, “The Toll->NFkappaB signaling pathway mediates the neuropathological effects of the human Alzheimer's Abeta42 polypeptide in Drosophila," PLoS ONE, vol. 3, no. 12, Article ID e3966, 2008.

[68] S. Rosales-Corral, R. J. Reiter, D.-X. Tan, G. G. Ortiz, and G. Lopez-Armas, "Functional aspects of redox control during neuroinflammation," Antioxidants and Redox Signaling, vol. 13, no. 2, pp. 193-247, 2010.

[69] J. A. Orellana, P. J. Sáez, K. F. Shoji et al., "Modulation of brain hemichannels and gap junction channels by pro-inflammatory agents and their possible role in neurodegeneration," Antioxidants and Redox Signaling, vol. 11, no. 2, pp. 369-399, 2009.

[70] N. F. Cruz, K. K. Ball, and G. A. Dienel, "Astrocytic gap junctional communication is reduced in amyloid- $\beta$-treated cultured astrocytes, but not in Alzheimer's disease transgenic mice," ASN Neuro, vol. 2, no. 4, Article ID e00041, 2010.

[71] M. A. Retamal, N. Froger, N. Palacios-Prado et al., "Cx43 hemichannels and gap junction channels in astrocytes are regulated oppositely by proinflammatory cytokines released from activated microglia," Journal of Neuroscience, vol. 27, no. 50, pp. 13781-13792, 2007.

[72] J. A. Orellana, K. F. Shoji, V. Abudara et al., "Amyloid $\beta$-induced death in neurons involves glial and neuronal hemichannels," Journal of Neuroscience, vol. 31, no. 13, pp. 4962-4977, 2011.

[73] C.-K. Liao, S.-M. Wang, Y.-L. Chen, H.-S. Wang, and J.C. Wu, "Lipopolysaccharide-induced inhibition of connexin 43 gap junction communication in astrocytes is mediated by downregulation of caveolin-3," International Journal of Biochemistry and Cell Biology, vol. 42, no. 5, pp. 762-770, 2010.

[74] J. A. Orellana, D. E. Hernández, P. Ezan et al., "Hypoxia in high glucose followed by reoxygenation in normal glucose reduces the viability of cortical astrocytes through increased permeability of connexin 43 hemichannels," GLIA, vol. 58, no. 3, pp. 329-343, 2010.

[75] J. A. Orellana, N. Froger, P. Ezan et al., "ATP and glutamate released via astroglial connexin 43 hemichannels mediate neuronal death through activation of pannexin 1 hemichannels," Journal of Neurochemistry, vol. 118, no. 5, pp. 826-840, 2011.

[76] A. Koulakoff, X. Mei, J. A. Orellana, J. C. Sáez, and C. Giaume, "Glial connexin expression and function in the context of Alzheimer's disease," Biochimica et Biophysica Acta, vol. 1818, no. 8, pp. 2048-2057, 2011.

[77] R. A. Quintanilla, J. A. Orellana, and R. von Bernhardi, "Understanding risk factors for Alzheimer's disease: interplay of neuroinflammation, connexin-based communication and oxidative stress," Archives of Medical Research, vol. 43, no. 8, pp. 632-644, 2012.

[78] R. N. Kalaria, "Microglia and Alzheimer's disease," Current Opinion in Hematology, vol. 6, no. 1, pp. 15-24, 1996.

[79] H. M. Wisniewski, J. Wegiel, K. C. Wang, M. Kujawa, and B. Lach, "Ultrastructural studies of the cells forming amyloid fibers in classical plaques," Canadian Journal of Neurological Sciences, vol. 16, no. 4, pp. 535-542, 1989.

[80] H. M. Wisniewski, J. Wegiel, K. C. Wang, and B. Lach, "Ultrastructural studies of the cells forming amyloid in the cortical vessel wall in Alzheimer's disease," Acta Neuropathologica, vol. 84, no. 2, pp. 117-127, 1992.

[81] T. K. Makar, M. Nedergaard, A. Preuss, A. S. Gelbard, A. S. Perumal, and A. J. L. Cooper, "Vitamin E, ascorbate, glutathione, glutathione disulfide, and enzymes of glutathione metabolism in cultures of chick astrocytes and neurons: evidence that astrocytes play an important role in antioxidative processes in the brain," Journal of Neurochemistry, vol. 62, no. 1, pp. 45-53, 1994.

[82] G. Ramírez, R. Toro, H. Döbeli, and R. Von Bernhardi, “Protection of rat primary hippocampal cultures from $\mathrm{A} \beta$ cytotoxicity by pro-inflammatory molecules is mediated by astrocytes," Neurobiology of Disease, vol. 19, no. 1-2, pp. 243-254, 2005.

[83] J. Tichauer, K. Saud, and R. Von Bernhardi, "Modulation by astrocytes of microglial cell-mediated neuroinflammation: effect on the activation of microglial signaling pathways," NeuroImmunoModulation, vol. 14, no. 3-4, pp. 168-174, 2007.

[84] J. Tichauer and R. von Bernhardi, "Relevance of TGFb Smad3 pathway modulation of scavenger receptor expression and microglial cell activation for Alzheimer disease," Journal of Neuroscience Research, vol. 90, no. 5, pp. 1970-1980, 2012.

[85] L. Arnaud, N. K. Robakis, and M. E. Figueiredo-Pereira, "It may take inflammation, phosphorylation and ubiquitination to 'tangle' in Alzheimer's disease," Neurodegenerative Diseases, vol. 3, no. 6, pp. 313-319, 2006.

[86] F. Checler, C. Alves Da Costa, K. Ancolio, N. Chevallier, E. Lopez-Perez, and P. Marambaud, "Role of the proteasome in Alzheimer's disease," Biochimica et Biophysica Acta, vol. 1502, no. 1, pp. 133-138, 2000.

[87] P. Rockwell, H. Yuan, R. Magnusson, and M. E. FigueiredoPereira, "Proteasome inhibition in neuronal cells induces a proinflammatory response manifested by upregulation of cyclooxygenase-2, its accumulation as ubiquitin conjugates, and production of the prostaglandin PGE2," Archives of Biochemistry and Biophysics, vol. 374, no. 2, pp. 325-333, 2000.

[88] M. D. Maldonado, R. J. Reiter, and M. A. Pérez-San-Gregorio, "Melatonin as a potential therapeutic agent in psychiatric illness," Human Psychopharmacology, vol. 24, no. 5, pp. 391-400, 2009.

[89] Y. A. Lam, C. M. Pickart, A. Alban et al., "Inhibition of the ubiquitin-proteasome system in Alzheimer's disease," Proceedings of the National Academy of Sciences of the United States of America, vol. 97, no. 18, pp. 9902-9906, 2000.

[90] P. Nahreini, C. Andreatta, and K. N. Prasad, "Proteasome activity is critical for the cAMP-induced differentiation of neuroblastoma cells," Cellular and Molecular Neurobiology, vol. 21, no. 5, pp. 509-521, 2001.

[91] B. Permanne, C. Adessi, G. P. Saborio et al., "Reduction of amyloid load and cerebral damage in a transgenic mouse model of Alzheimer's disease by treatment with a beta-sheet breaker peptide," The FASEB Journal, vol. 16, no. 8, pp. 860-862, 2002.

[92] C. K. Combs, J. Colleen Karlo, S.-C. Kao, and G. E. Landreth, " $\beta$-amyloid stimulation of microglia anti monocytes results in $\mathrm{TNF} \alpha$-dependent expression of inducible nitric oxide synthase and neuronal apoptosis," Journal of Neuroscience, vol. 21, no. 4, pp. 1179-1188, 2001. 
[93] G. J. Ho, R. Drego, E. Hakimian, and E. Masliah, "Mechanisms of cell signaling and inflammation in Alzheimer's disease," Current Drug Targets, vol. 4, no. 2, pp. 247-256, 2005.

[94] P. L. McGeer and E. G. McGeer, "Inflammation and the degenerative diseases of aging," Annals of the New York Academy of Sciences, vol. 1035, pp. 104-116, 2004.

[95] J. Bauer, S. Strauss, U. Schreiter-Gasser et al., "Interleukin-6 and $\alpha$-2-macroglobulin indicate an acute-phase state in Alzheimer's disease cortices," FEBS Letters, vol. 285, no. 1, pp. 111-114, 1991.

[96] E. N. Benveniste, S. M. Sparacio, J. G. Norris, H. E. Grenett, and G. M. Fuller, "Induction and regulation of interleukin- 6 gene expression in rat astrocytes," Journal of Neuroimmunology, vol. 30, no. 2-3, pp. 201-212, 1990.

[97] A. Klegeris and P. L. McGeer, "beta-amyloid protein enhances macrophage production of oxygen free radicals and glutamate," Journal of Neuroscience Research, vol. 49, no. 2, pp. 229-235, 1997.

[98] S. C. Lee, W. Liu, D. W. Dickson, C. F. Brosnan, and J. W. Berman, "Cytokine production by human fetal microglia and astrocytes: differential induction by lipopolysaccharide and IL1 $\beta$," Journal of Immunology, vol. 150, no. 7, pp. 2659-2667, 1993.

[99] K. W. Selmaj, M. Farooq, W. T. Norton, C. S. Raine, and C. F. Brosnan, "Proliferation of astrocytes in vitro in response to cytokines. A primary role for tumor necrosis factor," Journal of Immunology, vol. 144, no. 1, pp. 129-135, 1990.

[100] C. J. Heyser, E. Masliah, A. Samimi, I. L. Campbell, and L. H. Gold, "Progressive decline in avoidance learning paralleled by inflammatory neurodegeneration in transgenic mice expressing interleukin 6 in the brain," Proceedings of the National Academy of Sciences of the United States of America, vol. 94, no. 4, pp. 1500-1505, 1997.

[101] J. V. Castell, M. J. Gomez-Lechon, M. David et al., "Interleukin6 is the major regulator of acute phase protein synthesis in adult human hepatocytes," FEBS Letters, vol. 242, no. 2, pp. 237-239, 1989.

[102] J. Tan, T. Town, D. Paris et al., "Microglial activation resulting from CD40-CD40l interaction after $\beta$ - amyloid stimulation," Science, vol. 286, no. 5448, pp. 2352-2355, 1999.

[103] R. Horuk, A. W. Martin, Z.-X. Wang et al., "Expression of chemokine receptors by subsets of neurons in the central nervous system," Journal of Immunology, vol. 158, no. 6, pp. 2882-2890, 1997.

[104] M. Xia, S. Qin, M. McNamara, C. Mackay, and B. T. Hyman, "Interleukin-8 receptor B immunoreactivity in brain and neuritic plaques of Alzheimer's disease," The American Journal of Pathology, vol. 150, no. 4, pp. 1267-1274, 1997.

[105] D. Galimberti, N. Schoonenboom, P. Scheltens et al., "Intrathecal chemokine synthesis in mild cognitive impairment and Alzheimer disease," Archives of Neurology, vol. 63, no. 4, pp. 538$543,2006$.

[106] D. Galimberti, E. Venturelli, C. Fenoglio et al., "Intrathecal levels of IL-6, IL-11 and LIF in Alzheimer's disease and frontotemporal lobar degeneration," Journal of Neurology, vol. 255, no. 4, pp. 539-544, 2008.

[107] H. Wilms, J. Sievers, R. Dengler, J. Bufler, G. Deuschl, and R. Lucius, "Intrathecal synthesis of monocyte chemoattractant protein-1 (MCP-1) in amyotrophic lateral sclerosis: further evidence for microglial activation in neurodegeneration," Journal of Neuroimmunology, vol. 144, no. 1-2, pp. 139-142, 2003.

[108] J. Rogers, N. R. Cooper, S. Webster et al., "Complement activation by $\beta$-amyloid in Alzheimer disease," Proceedings of the
National Academy of Sciences of the United States of America, vol. 89, no. 21, pp. 10016-10020, 1992.

[109] Y. Shen and S. Meri, "Yin and Yang: complement activation and regulation in Alzheimer's disease," Progress in Neurobiology, vol. 70, no. 6, pp. 463-472, 2003.

[110] P. Mukherjee and G. M. Pasinetti, "The role of complement anaphylatoxin C5a in neurodegeneration: implications in Alzheimer's disease," Journal of Neuroimmunology, vol. 105, no. 2, pp. 124-130, 2000.

[111] S. S. Bohlson, D. A. Fraser, and A. J. Tenner, "Complement proteins $\mathrm{Clq}$ and $\mathrm{MBL}$ are pattern recognition molecules that signal immediate and long-term protective immune functions," Molecular Immunology, vol. 44, no. 1-3, pp. 33-43, 2007.

[112] E. Masliah, M. Mallory, L. Hansen et al., "Immunoreactivity of CD45, a protein phosphotyrosine phosphatase, in Alzheimer's disease," Acta Neuropathologica, vol. 83, no. 1, pp. 12-20, 1991.

[113] J. Tan, T. Town, T. Mori et al., "CD45 opposes $\beta$-amyloid peptide-induced microglial activation via inhibition of $\mathrm{p} 44 / 42$ mitogen-activated protein kinase," Journal of Neuroscience, vol. 20, no. 20, pp. 7587-7594, 2000.

[114] Y. Zhu, H. Hou, K. Rezai-Zadeh et al., "CD45 deficiency drives amyloid- $\beta$ peptide oligomers and neuronal loss in alzheimer's disease mice," Journal of Neuroscience, vol. 31, no. 4, pp. 13551365, 2011.

[115] S. S. Shaftel, S. Kyrkanides, J. A. Olschowka, J.-N. H. Miller, R. E. Johnson, and M. K. O'Banion, "Sustained hippocampal IL-1 $\beta$ overexpression mediates chronic neuroinflammation and ameliorates Alzheimer plaque pathology," Journal of Clinical Investigation, vol. 117, no. 6, pp. 1595-1604, 2007.

[116] P. Chakrabarty, C. Ceballos-Diaz, A. Beccard et al., "IFN$\gamma$ promotes complement expression and attenuates amyloid plaque deposition in amyloid $\beta$ precursor protein transgenic mice," Journal of Immunology, vol. 184, no. 9, pp. 5333-5343, 2010.

[117] T. M, Weitz, and T. Town, "Microglia in Alzheimer's disease: it's all about context," International Journal of Alzheimer's Disease, vol. 2012, Article ID 314185, 2012.

[118] A. Cagnin, M. Rossor, E. L. Sampson, T. MacKinnon, and R. B. Banati, "In vivo detection of microglial activation in frontotemporal dementia," Annals of Neurology, vol. 56, no. 6, pp. 894-897, 2004.

[119] R. B. Banati, J. Newcombe, R. N. Gunn et al., “The peripheral benzodiazepine binding site in the brain in multiple sclerosis. Quantitative in vivo imaging of microglia as a measure of disease activity," Brain, vol. 123, no. 11, pp. 2321-2337, 2000.

[120] S. B. Naphade, K. A. Kigerl, L. B. Jakeman, S. K. Kostyk, P. G. Popovich, and J. Kuret, "Progranulin expression is upregulated after spinal contusion in mice," Acta Neuropathologica, vol. 119, no. 1, pp. 123-133, 2010.

[121] Y. Tanaka, T. Matsuwaki, K. Yamanouchi, and M. Nishihara, "Exacerbated inflammatory responses related to activated microglia after traumatic brain injury in progranulin-deficient mice," Neuroscience, vol. 231, no. 2, pp. 49-60, 2013.

[122] K. R. Byrnes, P. M. Washington, S. M. Knoblach, E. Hoffman, and A. I. Faden, "Delayed inflammatory mRNA and protein expression after spinal cord injury," Journal of Neuroinflammation, vol. 8, no. 5, pp. 130-144, 2011.

[123] Y. Wang, H. Moges, Y. Bharucha, and A. Symes, "Smad3 null mice display more rapid wound closure and reduced scar formation after a stab wound to the cerebral cortex," Experimental Neurology, vol. 203, no. 1, pp. 168-184, 2007. 
[124] F. Yin, R. Banerjee, B. Thomas et al., "Exaggerated inflammation, impaired host defense, and neuropathology in progranulin-deficient mice," Journal of Experimental Medicine, vol. 207, no. 1, pp. 117-128, 2010.

[125] F. Yin, M. Dumont, R. Banerjee et al., "Behavioral deficits and progressive neuropathology in progranulin-deficient mice: a mouse model of frontotemporal dementia," FASEB Journal, vol. 24, no. 12, pp. 4639-4647, 2010.

[126] L. H. Martens, J. Zhang, S. J. Barmada et al., "Progranulin deficiency promotes neuroinflammation and neuron loss following toxin-induced injury," Journal of Clinical Investigation, vol. 122, no. 11, pp. 3955-3959, 2012.

[127] N. Brouwers, K. Sleegers, S. Engelborghs et al., "Genetic variability in progranulin contributes to risk for clinically diagnosed Alzheimer disease," Neurology, vol. 71, no. 9, pp. 656-664, 2008.

[128] F. Cortini, C. Fenoglio, I. Guidi et al., "Novel exon 1 progranulin gene variant in Alzheimer's disease," European Journal of Neurology, vol. 15, no. 10, pp. 1111-1117, 2008.

[129] G. Gliebus, A. Rosso, and C. F. Lippa, "Progranulin and $\beta$ amyloid distribution: a case report of the brain from preclinical ps-1 mutation carrier," The American Journal of Alzheimer's Disease and other Dementias, vol. 24, no. 6, pp. 456-460, 2009.

[130] S. Pereson, H. Wils, G. Kleinberger et al., "Progranulin expression correlates with dense-core amyloid plaque burden in Alzheimer disease mouse models," Journal of Pathology, vol. 219, no. 2, pp. 173-181, 2009.

[131] F. Pickford, J. Marcus, L. M. Camargo et al., "Progranulin is a chemoattractant for microglia and stimulates their endocytic activity," The American Journal of Pathology, vol. 178, no. 1, pp. 284-295, 2011.

[132] D. Uberti, G. Cantarella, F. Facchetti et al., "TRAIL is expressed in the brain cells of Alzheimer's disease patients," NeuroReport, vol. 15, no. 4, pp. 579-581, 2004.

[133] Y. Baba, M. C. Baker, I. Le Ber et al., "Clinical and genetic features of families with frontotemporal dementia and parkinsonism linked to chromosome 17 with a P301S tau mutation," Journal of Neural Transmission, vol. 114, no. 7, pp. 947-950, 2007.

[134] C. H. Reynolds, J. C. Betts, W. P. Blackstock, A. R. Nebreda, and B. H. Anderton, "Phosphorylation sites on tau identified by nanoelectrospray mass spectrometry: differences in vitro between the mitogen-activated protein kinases ERK2, c-Jun Nterminal kinase and P38, and glycogen synthase kinase- $3 \beta$," Journal of Neurochemistry, vol. 74, no. 4, pp. 1587-1595, 2000. 


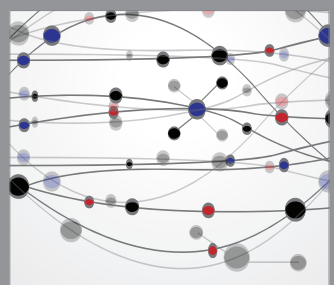

The Scientific World Journal
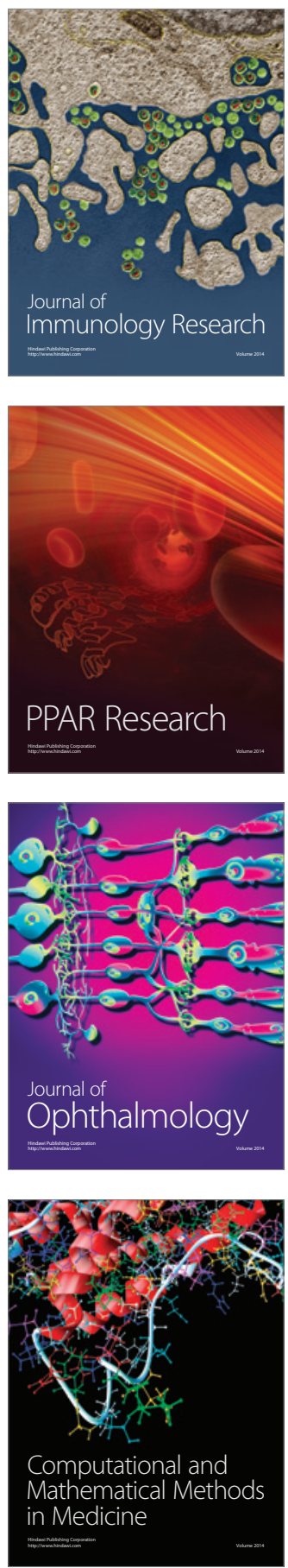

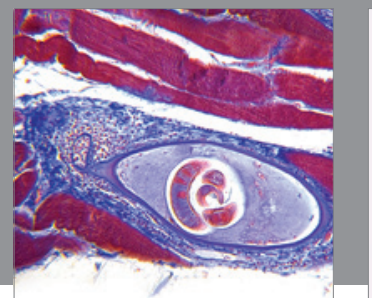

Gastroenterology

Research and Practice
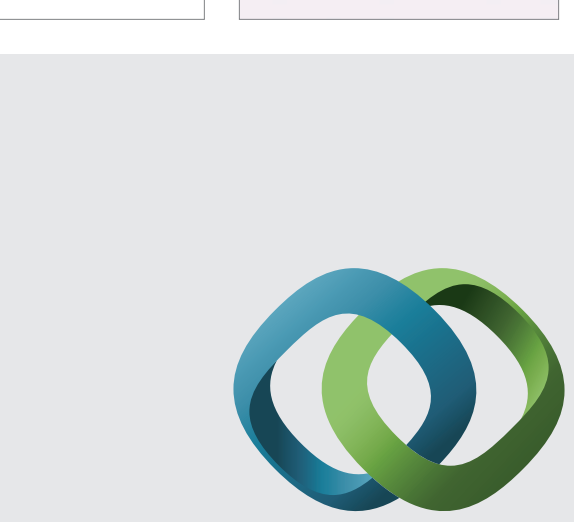

\section{Hindawi}

Submit your manuscripts at

http://www.hindawi.com
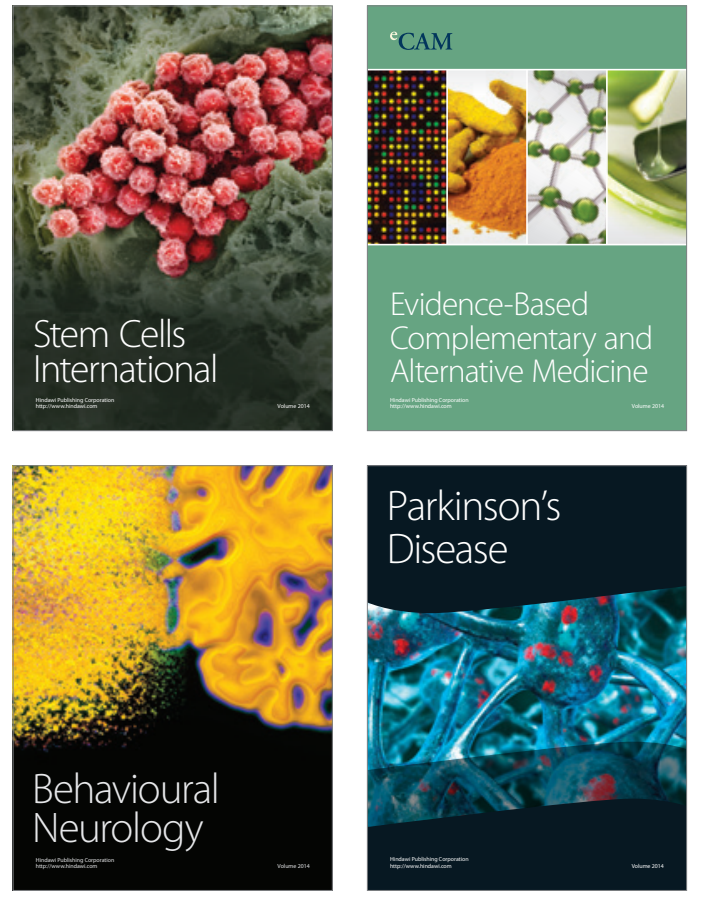
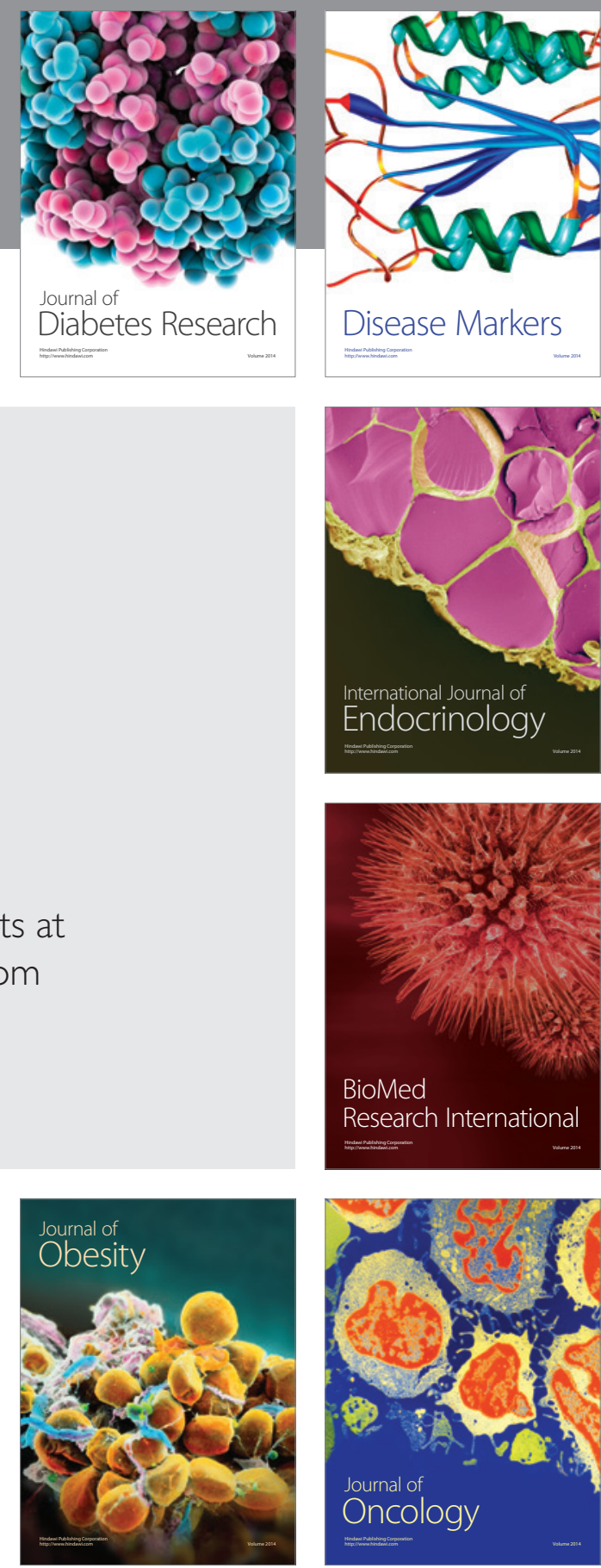

Disease Markers
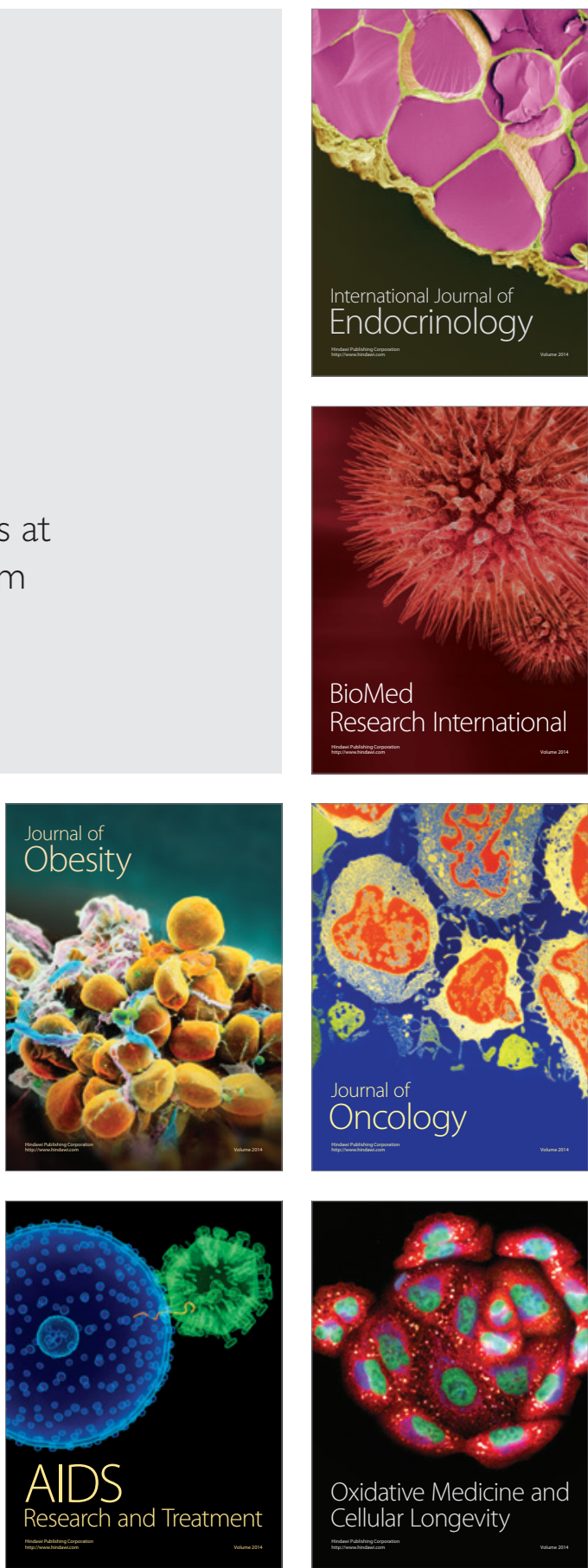